"This is an Author's Accepted Manuscript of an article published in International Review of Economics, Vol. 64, Issue 2, June 2017, pp.125-143. The final publication is available at https://link.springer.com/article/10.1007\%2Fs12232-016-0265-0 ". 


\section{International Review of Economics Poverty, Economic Stress and Quality of Life - Lessons from the Irish Case --Manuscript Draft--}

Manuscript Number:

Full Title:

Article Type:

Corresponding Author:

IREC-D-16-00028R1

Poverty, Economic Stress and Quality of Life - Lessons from the Irish Case

\section{S.I. : Happiness and Health}

Dorothy Watson, PhD

Economic and Social Research Institute

Dublin 2, IRELAND

\section{Corresponding Author Secondary} Information:

Corresponding Author's Institution:

Economic and Social Research Institute

Corresponding Author's Secondary Institution:

First Author:

Dorothy Watson, PhD

First Author Secondary Information:

Order of Authors:

Dorothy Watson, PhD

Bertrand Maître

Christopher T Whelan

Helen Russell

Order of Authors Secondary Information:

Funding Information:

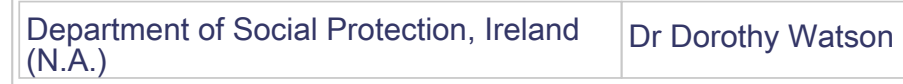

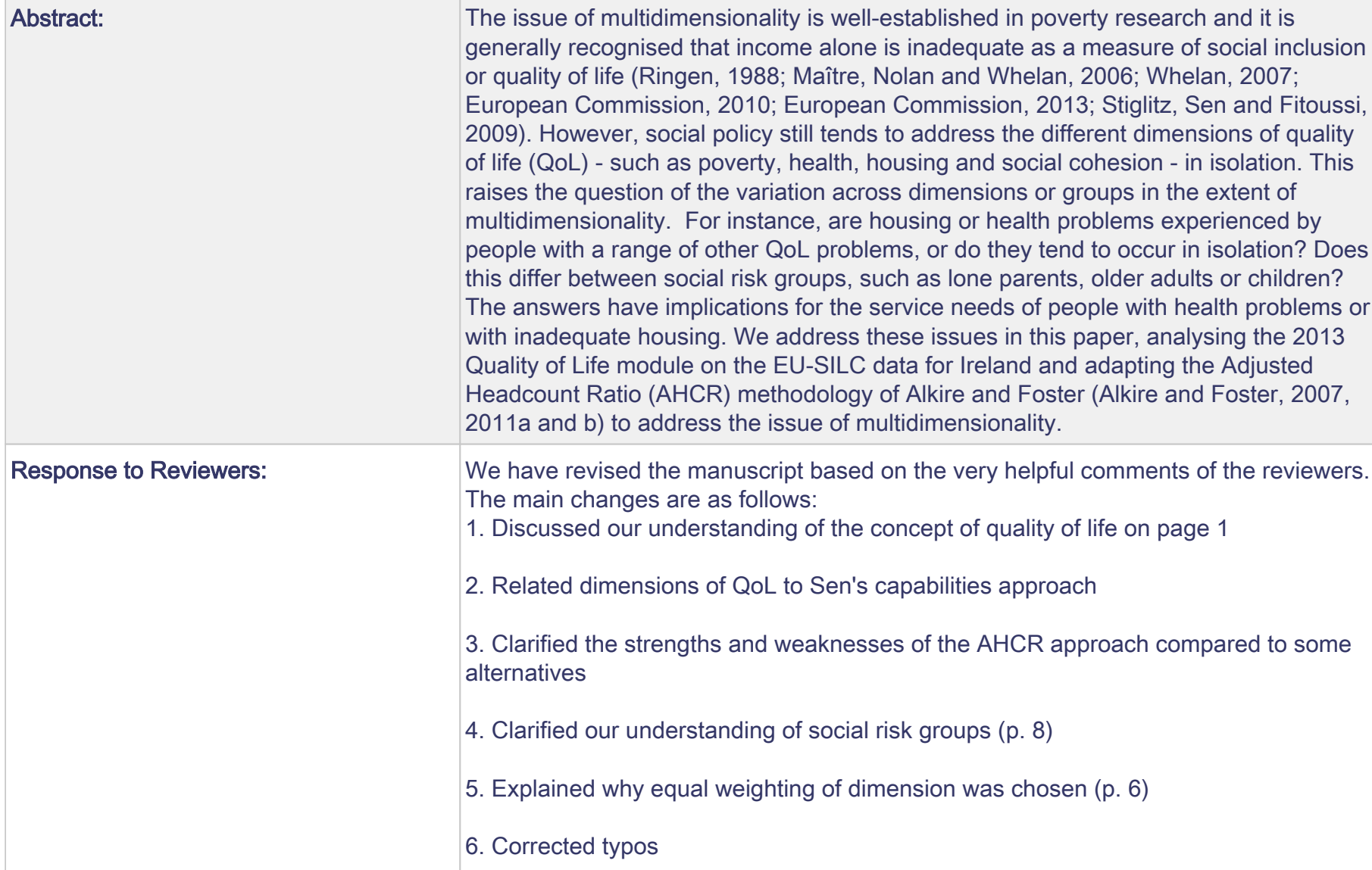


7. Based Figure 1 on all persons (not just adults)

Powered by Editorial Manager ${ }^{\circledR}$ and ProduXion Manager ${ }^{\circledR}$ from Aries Systems Corporation 


\title{
Poverty, Economic Stress and Quality of Life - Lessons from the Irish Case
}

\begin{abstract}
The issue of multidimensionality is well-established in poverty research and it is generally recognised that income alone is inadequate as a measure of social inclusion or quality of life (Ringen, 1988;

Maître, Nolan and Whelan, 2006; Whelan, 2007; European Commission, 2010; European Commission, 2013; Stiglitz, Sen and Fitoussi, 2009). However, social policy still tends to address the different dimensions of quality of life (QoL) - such as poverty, health, housing and social cohesion in isolation. This raises the question of the variation across dimensions or groups in the extent of multidimensionality. For instance, are housing or health problems experienced by people with a range of other QoL problems, or do they tend to occur in isolation? Does this differ between social risk groups, such as lone parents, older adults or children? The answers have implications for the service needs of people with health problems or with inadequate housing. We address these issues in this paper, analysing the 2013 Quality of Life module on the EU-SILC data for Ireland and adapting the Adjusted Headcount Ratio (AHCR) methodology of Alkire and Foster (Alkire and Foster, 2007, $2011 a$ and $b$ ) to address the issue of multidimensionality.
\end{abstract}

Keywords: Quality of Life; Multidimensionality; Poverty; Ireland; Adjusted Headcount Ratio

JEL codes: I140; I310; 1320 


\section{Introduction}

The issue of multidimensionality is well-established in discussions of poverty. Since the work of Townsend (1979) it is accepted that poverty does not simply consist of low income but that it is more broadly about the "inability to participate fully in society" due to a lack of resources (Townsend, 1979, p.31). There is now general recognition that income alone is inadequate as a measure of social inclusion or quality of life (QoL) (Ringen, 1988; Maître, Nolan and Whelan, 2006; Whelan, 2007; European Commission, 2010; European Commission, 2013; Stiglitz, Sen and Fitoussi, 2009). The multidimensional nature of poverty creates measurement challenges which have been an important focus of research (Moisio, 2004; Whelan and Maître, 2005; Whelan, Nolan and Maître, 2014; Kakwani and Silber, 2007). The academic and policy debates on such methodological approaches have highlighted a tension between the value of summary indices for communication to a wide audience and the potentially arbitrary nature of the decisions required in combining distinct dimensions.

However, there has been less emphasis on variations across social groups or dimensions in the extent of multidimensionality. For instance, are quality of life ( $Q \circ L)$ problems in dimensions such as housing or health experienced by people with a range of other QoL problems, or do they tend to occur in isolation? Does this differ between social risk groups, such as lone parents, older adults or children?

Approaching individual QoL domains from a multidimensional perspective involves asking whether housing problems, for instance, are experienced by people who also have a range of other quality of life problems. The extent to which this is true will have a bearing on whether housing policy needs to grapple with broader aspects of disadvantage or can focus on housing supply. It is this issue which is the focus of the present paper.

Our concept of quality of life is informed by the capabilities approach of Sen, which emphasises the type and range of things that people are enabled to do or to be (Sen, 1992, 1993, 2009). Income and, more broadly, resources are of instrumental importance as they condition that range of options in terms of what a person can be or do. From the perspective of QoL, resources are an important component of what enables people to have choices. However, resource-based measures are not a very precise indicator of what a person can be or do because people may have different needs which means that they may require different levels of resources in order to achieve the same outcomes. As Sen puts it, different "conversion" factors are involved. Also, some outcomes may not be responsive to differential resources. The capabilities approach is flexible enough to embrace non-material resources such as health and mental well-being, social support and a stable socio-political environment.

We draw on the 2013 Survey on Income and Living Conditions (SILC) data for Ireland to develop a multidimensional indicator of quality of life problems. In the spirit of going 'beyond GDP', this analysis considers quality of life more broadly. The decision to focus on the disadvantaged end of the spectrum (quality of life problems rather than quality of life in the positive sense) derives from a general concern with social exclusion: it is those who are particularly disadvantaged that are excluded from the normal or typical way of life of a community. 


\section{The challenge of capturing multidimensionality}

One challenge that must be faced in seeking to capture multidimensionality is the question of how to combine different dimensions. The 'counting' approach would involve summing the number of dimensions on which an individual is deemed to have a problem (Atkinson, 2003). Atkinson goes on to distinguish between the union and intersection approaches to counting dimensions. The union approach would count as poor or deprived anyone lacking on any of the dimensions. This is the approach adopted in the EU2020 target: the population 'at risk of poverty or exclusion' consists of those at-risk-of-poverty (i.e. below the $60 \%$ of median poverty threshold), or experiencing severe material deprivation (i.e. lacking at least four of nine basic goods and services) or being in a household with very low work intensity (VLWI) (i.e. a jobless household containing working-age adults). The intersection approach, on the other hand, is adopted in setting the Irish anti-poverty target. This target is defined in terms of 'consistent poverty' which involves being below the $60 \%$ of the median income poverty threshold and lacking 2 or more of 11 basic goods and services (Department of Social Protection, 2015).

The problem with the union and intersection approaches is that, as a consequence of the fact that deprivation dimensions tend to be more moderately correlated than is generally assumed, they tend not to perform particularly well in terms of identifying the poor. Where the number of dimensions is large, the union approach can result in the identification of an implausibly large group while the intersection approach can result in the identification of an extremely small minority (Whelan, Nolan and Maître, 2014).

A number of increasingly sophisticated approaches to the issue of multidimensionality have been developed to address these problems. In this paper we take as a starting point a specific multidimensional approach with clearly understood axiomatic properties, namely the one developed by Alkire and Foster (2007, 2011a and b). This is a methodology that allows one to examine differences between groups in both the levels and patterns of multidimensional disadvantage. We extend it in this paper to ask the extent to which an individual with problems on one QoL dimension is likely to have problems on multiple other dimensions as well.

A number of authors have questioned the need for a multidimensional poverty index (Ravillion, 2011) and there has been robust debate relating to the merits of an aggregate indicator such as the composite United Nations Development Programme (UNDP) Human Development Index versus the set of Millenium Development Goals which avoid such aggregation. Without arbitrating on the relative value of these alternatives, here we maintain the position that where a multidimensional index is constructed, there is much to be gained from adopting an approach that with clearly understood axiomatic properties.

\section{Methodology}

Data

The data are from the 2013 Survey on Income and Living Conditions (SILC) for Ireland, an instrument designed to provide statistics on household and individual income as well as related indicators of living standards, poverty and inequality (CSO, 2013). Within each household, every adult (aged 16 and over) is interviewed face-to-face and detailed information is also collected on the household as a whole. The total sample size in 2013 was 4,922 households and 12,663 individuals. 
The SILC sample is re-weighted to ensure that it is representative of the population, including design weights and re-calibration on the basis of age by sex (four age categories), region (eight regions) and household composition (six categories) (CSO 2012, p. 88).

In 2013, a special module was added to the SILC survey designed to capture a range of dimensions of quality of life (QoL) in addition to the core variables collected in every wave. The QoL module was completed by adults in the household who were interviewed directly (i.e. excluding those interviewed by proxy). We excluded the population interviewed by proxy. The rate of proxy interviews in SILC 2013 for Ireland was high (at about 35 per cent), so that the module data was available for just over 6,100 adults, or 65 per cent of those over the age of 16 in the SILC 2013 households. In order to include children in the analysis here, we attribute the AHCR score of the mother to the children in a household.

\section{Adjusted Headcount Ratio (AHCR) methodology}

This methodology originated in the economic literature on the multidimensionality of poverty and inequality that was largely influenced by the work of Amartya Sen $(1979 ; 1985 ; 1992,1999)$. The approach initially focused on multidimensional poverty in the developing world (CONEVAL, 2010; Alkire and Santos, 2010, 2014; Angulo et al., 2013; Ministerio de Desarrollo Social, 2015). Recent work has applied this approach to developed countries and have examined the situation in the US and Europe (Alkire et al, 2012; Watson, Maître and Kingston, 2014; Whelan et al., 2014; Williams et al., 2014; Dhongde and Haveman, 2016). Alkire and Foster (2011) demonstrate that their methodology is characterised by a number of desirable axiomatic properties. Of particular relevance for our analysis is decomposability in relation to dimensions and socio-economic groups.

The AHCR methodology is structured around three distinct choices (Alkire and Foster, 2007, 2011a and $b$ ). These are:

\section{The choice of dimensions and indicators (and weights)}

2. The choice of indicator thresholds - this is the threshold on each indicator beyond which an individual will be regarded as 'deprived' or as 'experiencing a deficit'.

3. The choice of overall multidimensional threshold - this is the decision regarding on how many indicators someone must experience problems before they are regarded as having multidimensional QoL problems.

It should be clear that the AHCR methodology as such has nothing to say regarding the number and type of dimensions to be included in the analysis. In choosing the dimensions in the present analysis we have drawn on the set of QoL items included in the 2013 SILC module, as well as a number of items from the core of SILC. There is no universally agreed set of dimensions of quality of life, with several studies opting for different sets of dimensions (Fahey et al., 2005; Layte et al., 2010; Sen, 1992, 1993; NESC, 2009; Canadian Index of Well-being (CIW), 2012; OECD Better Life Index; Watson, Pichler and Wallace, 2010; Sponsorship Group on Measuring Progress, Well-being and Sustainable Development, 2011; Eurostat, 2015).

In the current analysis we have drawn on previous analysis at EU level in order to identify a set of dimensions that allows our findings to be located in a wider comparative context (Eurostat, 2015). An alternative approach would involve employing clustering techniques such as latent class analysis or self-organising maps). Such techniques differ in terms of the extent to which they involve prior 
assumptions relating to the number and type of dimensions involved and the optimum thresholds relating to constituent items. In general there tends to be a trade-off between the strength of prior assumptions and the challenges presented by post hoc interpretation of the findings (Pisati et al., 2010; Whelan et al., 2010). Further analysis would be valuable in establishing the extent to which the conclusions deriving from the current analysis are affected by our choice of dimensions based on substantive rather than statistical considerations.

A number of considerations inform the choice of dimensions. First, the dimensions must correspond to the unit of analysis. Since we analyse individuals and households, aggregate indicators such as the Gini coefficient are not useful because they do not vary across individuals within countries. Second, the indicator should be relevant to all of the groups being compared. Where we compare levels of QoL problems for people at different stages of the life-cycle, dimensions specific to particular lifecycle stages (such as work-life balance or access to child care) are not appropriate. Finally, the nature of the analysis with respect to causal inference will also have an influence on whether or not certain dimensions are included. It would not be possible to assess the impact of having a disability on quality of life, as we wish to do here, if one included disability as a component of the QoL indicator (as in Dhonge and Haveman, 2016 or Mitra and Brucker, 2014). As Whelan and Whelan (1995) argue, an uncritical insistence on multidimensionality in the indicator could paradoxically have the effect of obscuring the processes involved in generating social exclusion.

The dimensions chosen are shown in Table 1. Given the focus on social inclusion, it was important to include the two Irish national indicators of poverty: income poverty and deprivation. The other dimensions were financial strain, poor health, mental distress, crowding, housing quality problems, neighbourhood problems, and institutional mistrust, lack of social support and lack of safety.

From the capability perspective, income is an important resource and income poverty is a mark of inadequate resources. Deprivation and financial strain capture elements of the extent to which the available material resources meet the households' needs. This will be sensitive to differences in 'conversion factors' which will be influenced by characteristics of the household (such as need for childcare, presence of disability) and also the socio-political context (range of services that are 'decommodified' or provided by the state versus needing to be purchased on the market, EspingAndersen, 1990, 2002). Health problems and mental distress capture elements of the individual's personal or embodied resources or the lack thereof. These are both resources and also indicators of the cumulative impact of a history of negative material and social experiences as evidenced by the social gradient in health (Marmot. 2015). Crowding and housing quality problems are indicators of QoL problems in the area of housing - evidence of a reduced capability. Neighbourhood problems, institutional mistrust, lack of social support and lack of safety are all aspects of the quality of society and community which may be a drain on the individual's personal or material resources or may contribute to personal and social resilience.

Having chosen the indicators, we now need to decide at what level the person will be regarded as having a QoL problem on each indicator. If we have an item with a yes/no response, then the choice is limited to taking the group with the 'yes' responses as having a quality of life deficit. Where there is a range of responses or a scale, there is an element of arbitrariness in deciding on a threshold on the basis of which to identify those with QoL problems. One wants to identify a group for whom the problem is in some sense significant. The rationale we adopt here, following Whelan, Nolan and Maître (2014) is to take the income poverty rate (at-risk-of-poverty rate) as a benchmark. Income 
poverty is a widely-used indicator of poverty in the EU as well as in Ireland. In 2013 the income poverty rate across the entire population in Ireland was 15.2 per cent. We choose the threshold on each QoL indicator that identifies a group that is as close as possible in size to the overall percentage of people who are at-risk-of-poverty. This threshold has the merit of being linked to an indicator of social exclusion that has broad acceptance in European social policy. The thresholds were developed for the population of adults interviewed directly and, as noted above, the scores of the parent were applied to children.

\section{[Table 1 here]}

Each of the dimensions was weighted equally, following Whelan, Nolan and Maître (2014). For some purposes it might be appropriate to give the items different weights. For instance, if the items captured whether or not a household could afford each of a set of goods or services, we might give a higher weight to those deemed more important to 'essential' according to certain external criteria. For instance, it might be the case that lack of access to adequate heating for the home was more 'important' than an inability to afford to replace worn-out furniture. Consideration of weighting would be particularly important where the thresholds on the items were very different but, as we shall see in the next step, we adopt a similar threshold across all items. Given our research question here, however, an equal weighting of the items is more appropriate. We are essentially interested in whether those meeting a certain threshold (in terms of the population percent deprived) on one domain will meet the same threshold on multiple domains. The interpretation of the results would be difficult if different thresholds had been used on the different domains.

The third column of Table 1 shows the percentage identified as experiencing disadvantage on each dimension. The thresholds were developed on the basis of responses from the adults aged 16 and over who were interviewed directly, and the figures for this group are shown in Table 1. Their income poverty rate is a little lower (14.6 per cent) than for the general population, because the rate of income poverty is higher for children who are not included here.

The threshold for the deprivation items was 4 or more items which is higher than the national basic deprivation threshold of 2 or more. This is because the level of basic deprivation (close to 30 per cent across the entire population in $\mathbf{2 0 1 3}$ were unable to afford two or more of the items) was much higher than the 15.2 per cent which is the target cut-off here. In fact, the level identified by the 4+ threshold is 13 per cent, which is much closer to the target.

Apart from lacking social support, the range across the dimensions is from about 13 per cent to about 20 per cent. The threshold on the indicator for lacking social support is lower at just 6.7 per cent, because very few people identify a lack of social support on these indicators.

The second threshold is used to determine whether a person has deficits on a sufficient number of dimensions to be considered as having multidimensional QoL problems. Thus in order to be considered as having multidimensional QoL problems - as opposed to having problems with particular dimensions - an individual must be above the appropriate dimension-specific threshold on the requisite number of dimensions (Whelan, Nolan and Maître, 2014).

Figure 1 shows the percentage of the adults who exceeded the threshold on each number of dimensions. The union and intersection approach to capturing multidimensionality can be illustrated with respect to Figure 1. If we were to regard someone experiencing any of these quality of life problems - the union approach - this would identify close to 70 per cent of the population as 
having multidimensional QoL deficits. This is clearly so high as to compromise its usefulness. Further, experience can be viewed as 'multidimensional' in terms of the dimensions distinguished here. At the other extreme, if we required someone to be experiencing problems on all eleven of the dimensions, we would identify nobody as having multidimensional QoL problems.

[Figure 1 here]

Again, there is a certain level of arbitrariness in deciding on where to set this threshold. Choosing a threshold of three or more indicators would identify 27.8 per cent of persons as experiencing multiple QoL deficits, while a threshold of four or more indicators would identify 15.4 per cent. Identifying the larger group (27.8 per cent) has the merit of making more cases available within subgroups (such as age groups or social classes) for whom the AHCR could be decomposed. Therefore, we adopt the threshold of three or more here: someone experiencing problems on three or more of the indicators is regarded as having multidimensional quality of life problems.

\section{Measuring Social Risk Groups}

We distinguish social risk groups on the basis of their different capacities to meet their needs through paid work, either directly through their own work or indirectly through work of other family members. They are characterised by different kinds of challenges or barriers to participation in employment, which is the main way of accessing resources for those without substantial capital. This is different from social class differences which we would see as distinctions that operate within the market rather than barriers to market participation. The kinds of challenges might be linked to:

- Life cycle stage: children and people older than 'working age' adults

- Personal resources: illness or disability may limit a person's capacity to work as well as involving additional costs associated with treatment, medication or disability-specific devices and aids.

- Non-work responsibilities: responsibility for child care or others who have an illness or disability is likely to reduce the time available for paid work.

In the context of a capabilities approach, different social risk groups could also be seen as reflecting both differential needs and differential capacity to convert resources into capabilities. For instance, many people with a disability face higher costs associated with the disability itself, so that fewer resources are available for other things. Different life-course stages also tend to be associated with differential needs, with the highest levels of need for material resources typically found in the household formation and family formation stages. Table 2 shows the social risk groups we identify and the percentage of the population in each in 2013.

\section{[Table 2 here]}

It is possible to identify other dimensions of differentiation such as those based on employment/ unemployment or differences in human capital - skills, education, experience, time out of work and so on. However, we would argue that these subdivisions are better regarded as sources of variation within social risk groups (such as among lone parents or other working-age adults) rather than as constituting distinct social risk groups. Levels and types of education are consequential in terms of social class position, that is, with market power. Having a job, or not, once the person is seeking work is also a consequence both of market power of the individual and of overall demand for labour (which is influenced by the business cycle). 


\section{Quality of life problems by social risk: Level and Decomposition}

As well as having the advantage of being explicit regarding the decisions made in constructing the index, an important strength of the AHCR approach is in allowing comparisons between groups in terms of both the level and the composition of their disadvantage (Alkire and Foster, 2011b). This means that it is possible to calculate the contribution of each dimension to the AHCR for different groups and the proportion of the total population AHCR accounted for by each socio-economic group (Whelan, Nolan and Maître, 2014).

Three different indicators of the level of multidimensional disadvantage can be derived from the AHCR methodology, as illustrated in Table 3. The head count $(H)$ is the proportion of people who are experiencing multidimensional QoL deficits - the percentage experiencing 3 or more quality of life problems. As noted above, this is 27.8 per cent overall. It ranges from 54 per cent for working age adults with a disability and 46 per cent for lone parents down to 18 per cent for other adults age 30 to 65 and 20 per cent for those aged 66 and over. The ratio of highest to lowest is 2.9 .

[Table 3 here]

The intensity $(\mathrm{I})$ is the average deficit score for those experiencing multidimensional QoL deficits the proportion of the QoL indicators on which they experience a deficit. This is 37.6 per cent in the present case, indicating that those who are experiencing three or more QoL problems have problems on roughly one third of dimensions included, or just over 4 of the 11 indicators. The intensity ranges from 33 per cent to 42 per cent across social risk groups. Intensity tends to be higher for the groups with the highest headcount but differences by intensity are more muted than differences in headcount

The third indicator of the level of multidimensional QoL problems is the adjusted head count ratio (AHCR). This is the product of the head count and the intensity, with the intensity set to zero for cases where person is below the three or more threshold. The AHCR is 10.5 out of 100 for the total population. This does not refer to a percentage of the population - that is what the headcount does - but rather to the proportion of the total problems possible (i.e. if all the population had all eleven problems) that is found in the population. A score of zero would indicate that no member of the population experiences problems with 3 or more of the QoL indicators. A score of 100 would indicate that all members of the population have problems with the maximum possible number of QoL indicators - a highly unlikely occurrence. The AHCR figure is particularly useful when comparing different groups in the population, as we do for social risk groups. It ranges from 6 to 22 per cent by social risk group. Differences between groups are mainly driven by the headcount rather than the intensity which does not differ a great deal between those that are already above the $3+$ threshold.

As Alkire et al. (2015:188-189) note, from a capability perspective a higher value of AHCR is interpreted as representing more 'unfreedom'. Deprivations among the poor can be interpreted as them not having the capability to achieve the associated functionings under the following assumptions regarding the parameters:

(a) Indicators measure (or proxy) functionings or capabilities;

(b) People generally value being below the deprivation cut-off level of each indicator;

(c) Weighting choices are defensible;

(d) The cross dimensional poverty cut-off reflects who is capability-poor. 
The decomposition in the final column of Table 3 shows the percentage of the total package of QoL problems in the population that is accounted for by the problems in each social risk group. It will be a function of the sizes of the groups as shown in Table 2 and the level of problems as shown in the AHCR column in Table 3. In terms of social risk group, other adults age 30 to 65 account for 23 per cent of the total. Although the level of social risk problems in this group is relatively low, it is a large group, particularly compared to lone parents and working age adults with a disability. Nevertheless, lone parents and their children account for 19 per cent of QoL problems while working age disabled adults and their children account for 26 per cent.

\section{Decomposition of multidimensional QoL by dimension}

One of the advantages of the adjusted head count ratio measure is that it is decomposable not only in terms of group, as we saw above, but also in terms of dimensions of QoL within groups. This decomposition is not the same as the percentage of the population who have problems on each dimension but the contribution of each dimension to the overall QoL deficit 'package' (or AHCR) of the group. For instance, roughly 15 per cent of the population experience income poverty and income poverty contributes roughly 8 per cent to the total AHCR. The figure for the decomposition is lower not only because the decomposition must sum to 100 but also because not all of those who are deprived on each dimension have problems on 3 or more dimensions. ${ }^{1}$

From the second column of Table 4 we can see that six of the eleven items each contribute 10-11 per cent to the AHCR (deprivation, financial strain, mental distress, crowding, housing quality, neighbourhood problems). At the other end of the scale, lack of social support and lack of safety each contribute less than 6 per cent; in one case because the indicator has a low prevalence in the population (lack of social support) and in the other because the indicator is less likely to occur as part of a multidimensional complex of problems (lack of sense of safety).

In the second column, we began with the observation of multidimensionality and asked how 'central' the different dimensions were in terms of their contribution to the totality of multidimensional QoL problems. It is also possible to approach the question from another perspective, which is an extension to the AHCR approach. This would be to begin with the different dimensions (income poverty, health, deprivation etc.) and ask to what extent the 15 per cent of the population with the greatest problems on each dimension have multiple other QoL problems. This question might be of interest to in health policy, for example, since the presence of problems related to housing, lack of social support and so on would have implications for service needs of those with health problems. We focus on the headcount because there is little variation in intensity by social risk group and most of the difference between groups in the AHCR is driven by differences in the headcount.

\section{[Table 4 here]}

The third column of the table shows the percentage of those who are deprived on each indicator who have problems on multiple (three or more) indicators. We could term this the multidimensionality quotient (MQ) - the proportion of the specific kinds of QoL problem that is found among those with multidimensional problems. It varies by dimension, as can be seem in Table

\footnotetext{
${ }^{1}$ The percentage of the income poor who have 3 or more of the eleven QoL problems is shown in the third column of Table 4, discussed below.
} 
4. The figure is over 70 per cent for four of the indicators: deprivation, financial stress, mental distress and lack of social support. Where these individual QoL problems occur, they are likely to be part of a constellation of QoL problems. On the other hand, crowding, neighbourhood problems and lack of safety are found as part of such a constellation in between 50 and 59 per cent of cases. Income poverty is only slightly above this at 61.4 per cent. Neighbourhood problems, lack of safety and income poverty are somewhat less central than the other ten indicators to multidimensional QoL problems in the sense that they are slightly more likely than the other indicators to be found in the absence of other QoL problems.

\section{Decomposition of by dimension within social risk group}

As well as the decomposition by social risk group and by dimension, the AHCR can be decomposed by dimension within social risk group. This is shown in Figure 2. The indicators are sorted so that those that do not vary very much by social group are at the bottom of the chart to make it easier to see which dimensions differ by group. The most noticeable pattern is that the relative importance of the dimensions differs markedly between those over age 66 and younger adults and children.

Looking across dimensions, the differences between the social risk groups are most noticeable for poor health, lack of safety, crowding and financial stress. Poor health and lack of safety are more significant for older adults than for their younger counterparts. Poor health is also more significant for working age adults with a disability and mental distress is also relatively more important for this group. Financial stress and crowding, on the other hand, are relatively more significant among households with children. Crowding, in particular, declines very sharply with age, accounting for less than 1 per cent of the QoL problems of adults age 66 and over, compared to 21 per cent among children. Poverty and deprivation are most significant for lone parents and their children and mistrust in institutions is relatively more important for adults under age 30.

Problems with housing quality, lack of social support and neighbourhood problems do not differ a great deal in their relative contribution to the AHCR across social risk groups.

[Figure 2 here]

\section{Proportion of those with each kind of problem who have multiple other problems}

We can also bring a second perspective to bear on variations in the manner in which dimensions of deprivation are interlinked in the population as a whole by focusing on the multidimensionality quotient broken down by social risk group. Do the social risk groups differ in terms of whether any particular QoL problem will occur on its own or be part of a multidimensional constellation of QoL problems? Since the level of multidimensional QoL problems (both the headcount and AHCR) is high for families of lone parents and adults with a disability, then any particular QoL problem for these groups is likely to co-occur with several others. The average $M Q$ across dimensions is shown in the last column of the table beneath Figure 3. However, if we take the higher MQ for some groups as read, we can shift the focus to the relative $M Q$ for the different items within group by dividing by the average MQ across items. This allows us to compare by dimension within groups and ask whether those experiencing deprivation on a specific QoL dimension are more or less likely than average across dimensions for the group to be found among those with at least three QoL problems. For instance, the MQ for deprivation is 85.5 per cent for lone parents and their children compared to an average $\mathrm{MQ}$ across dimensions of 78.5 per cent. The relative $\mathrm{MQ}$ is $85.5 / 78.5$ or 1.09 . Deprivation is 
somewhat more likely than the other dimensions, then, to occur together with at least two other types of QoL problems for lone parent families.

[Figure 3 here]

The relative $M Q$ is shown Figure 3. Here we combine lone parents and their children and workingage adults with a disability and their children in order to have a sample of sufficient size. Some figures are not produced for older adults because the number of cases is too low for the types of QoL problem that are uncommon in this group (crowding and financial stress). Among lone parents and their children, the relative MQ fluctuates in a narrow range from 0.9 to 1.1. The range is a little wider for working-age adults with a disability and their children, extending from 0.8 for crowding to 1.2 for lack of support. Among other children, the MQ ranges from 0.7 for crowding to 1.4 for deprivation. This indicates that crowding for this group is less often found as part of a constellation of 3+ quality of life problems but that deprivation is a central component of multiple QoL problems. Among other adults under age 66, although the average MQ is lower than for other children, the relative pattern across dimensions within the groups are quite similar, with a high relative score for material deprivation and low relative scores for neighbourhood problems and crowding. However, it is older adults who emerge as most distinctive in terms of the relative MQ of the dimensions.

Although the average level of $M Q$ is low for this group at 54 per cent, the relative $M Q$ by dimension ranges from only about 0.6 times this figure for income poverty to 1.6 times this figure for deprivation. The relative $M Q$ is also low (about 0.8 ) for health problems, lack of support and feeling unsafe while it is high (1.3) for mental distress. The very low relative MQ for income poverty for older adults is linked to the fact that the basic State Pension rate was protected during the recession so that most pensioners are just above the income poverty threshold.

The overall picture is one where deprivation remains highly indicative of multidimensional QoL problems, even where the overall MQ is low. On the other hand, QoL problems related to crowding, neighbourhood problems and lack of safety are somewhat more likely to occur in the absence of other QoL problems.

\section{Discussion and Implications}

In this paper, we drew on the AHCR methodology to examine the extent to which different social risk groups experienced multidimensional QoL problems. We found differences in the level of multidimensional QoL problems by social risk group and also distinctive compositional patterns, particularly for older adults.

We saw that overall levels of multidimensional QoL problems tended to be higher for lone parents and their children and for working age adults with a disability and their children, with between 46 per cent and 54 per cent having three or more problems. By comparison, the rates for other children, young adults, other working age adults and older adults were much lower, falling in the range from 18 per cent to 26 per cent. The AHCR, which takes account of the number of QoL problems as well as the percentage with three or more problems, follows a similar pattern across groups.

The differences in the composition of multidimensional QoL problems across social risk groups were particularly evident for poor health, lack of safety, crowding, financial stress, mental distress and mistrust in institutions. As we might expect, poor health was relatively more important for older adults and those with a disability. Mental distress was also more significant among working age 
adults with a disability. Financial stress and crowding were more common among families with children. Mistrust in institutions was more prevalent among young adults while poverty and deprivation were relatively more significant among lone parents.

Another aspect of the analysis was to investigate the extent to which specific QoL problems, when they occur, are likely to affect the population already experiencing several other QoL problems. Taking a threshold of the most disadvantaged 15 per cent on each dimension means that the comparison does not necessarily have an absolute referent but it is useful in comparing across dimensions. The analysis showed that the extent to which the most disadvantaged 15 per cent on a particular dimension have three or more distinct problems ranges from about one half to about four fifths. The highest figures are for deprivation, financial strain, mental distress and lack of social support. The lowest figures, but still over one half, are for crowding, income poverty, lack of safety and health. The main differences in this respect by social risk group are found for older adults, for whom deprivation, is more likely than income poverty, lack of support and lack of safety to be found among those who already experience at least two other problems.

The extent of multidimensional disadvantage was striking. When we take the most disadvantaged 15 per cent on a range of QoL dimensions, we find that at least half of those with any specific kind of problem have at least two other QoL problems. Certain kinds of problems rarely occur on their own (deprivation and mental distress in particular). This has implications for the design of policy and services which need to take account of the multidimensionality of disadvantage. In designing mental health policy, for instance, it needs to be acknowledged that well over half of those experiencing mental distress are likely to have several other QoL problems. Crowding and neighbourhood problems were less likely to be found among those with multiple other issues, but even here over half of the most affected fifteen percent had at least two other QoL issues.

Our analysis confirms a variety of earlier finding showing that the correlation between income poverty and other dimensions of deprivation is both modest and variable across dimensions reflecting variability in the range of socio-economic factors that contribute to the distinct outcomes (Nolan and Whelan, 2011, Whelan and Maître, 2012). However, the possibility exists that the magnitude of this effect is exacerbated by the fact that Ireland was particularly badly affected by the Great Recession where falling incomes meant a corresponding fall in the poverty threshold. As a result, the income poverty level remained relatively flat after the onset of the recession and the relative nature of the measure meant that it did not capture the income drop faced by almost all households. The lower overlap between income poverty and the other dimensions might be partially a consequence of the behaviour of this relative measure in a period where falling incomes became pervasive.

\section{Compliance with Ethical Standards}

An earlier version of this paper was funded by the Social Inclusion Division of the Department of Social Protection in Ireland.

The authors declare that they have no conflict of interests. 


\section{References}

Alkire, S. and Foster, J. (2007), 'Counting and multidimensional poverty measurement', Oxford Poverty \& Human Development Initiative, OPHI Working Paper 7.

Alkire, S. and Foster, J. (2011a), 'Understandings and misunderstandings of multidimensional poverty measurement', Journal of Economic Inequality, Vol. 9, pp. 289-314

Alkire, S. and Foster, J. (2011b), 'Counting and Multidimensional Poverty', Journal of Public Economics, Vol. 95, No.7-8, pp.476-487

Alkire, S., Apablaza, M. \& Jung, E. (2012), 'Multidimensional poverty measurement for EU-SILC (European Union Statistics on Income and Living Conditions) countries', OPHI Research in Progress 36a.

Alkire, S. and Santos, M. E. (2010). 'Acute multidimensional poverty: A new index for developing countries',. Oxford Poverty \& Human Development Initiative ,OPHI Working Paper 38. Oxford: University of Oxford.

Alkire, S. and Santos, M. E. (2014). 'Measuring acute poverty in the developing world: Robustness and scope of the Multidimensional Poverty Index'. World Development, 52, 71-91.

Angulo, R., Díaz, B. Y. and Pardo Pinzón, R. (2013). 'A counting multidimensional poverty index in public policy context: The case of Colombia', Oxford Poverty \& Human Development Initiative OPHI Working Paper 62. Oxford: University of Oxford.

Atkinson A. (2003) 'Multidimensional Deprivation: Contrasting Social Welfare and Counting Approaches', Journal of Economic Inequality 1: 51-65.

Canadian Index of Wellbeing (2012). How are Canadians Really Doing? The 2012 CIW Report. Waterloo, ON: Canadian Index of Wellbeing and University of Waterloo.

Central Statistics Office (CSO) (2012). Survey on Income and Living Conditions, 2010. Dublin: Stationery Office.

Central Statistics Office (CSO) (2013), Survey on Income and Living Conditions(SILC): Questionnaire Manual, Quarters $3 \& 4$ 2013. Dublin: Central Statistics Office

Central Statistics Office (CSO), (2015) Survey of Income and Living Conditions (SILC) 2013. Dublin: Central Statistics Office.

CONEVAL (Consejo Nacional de Evaluación de la Política de Desarrollo Social de México) (2010). Informe de pobreza multidimensional en México 2008. CONEVAL. México.

Department of Social Protection (2015). Social Inclusion Report Incorporating Annual Reports for 2013 \& 2014. Dublin: Department of Social Protection.

Shatakshee Dhongde, S. and Haveman, R. (2016) Multi-Dimensional Deprivation in the U.S. Social Indicators Research, doi: 10.1007/s11205-016-1379-1

Erikson, R. and J. H. Goldthorpe (1993) The Constant Flux. Oxford: Oxford University Press.

Esping-Andersen, G., 1990, The Three Worlds of Welfare Capitalism, Oxford: Polity Press.

Esping-Andersen, G. (2002) 'Towards the Good Society, Once Again?' pp. 1-25 in Esping-Andersen (ed.) Why we Need a New Welfare State. Oxford: Oxford University Press.

European Commission (2010) The European Platform against Poverty and Social Exclusion: $A$ European framework for social and territorial cohesion, Brussels: European Commission 
European Commission (2011) Employment and Social Developments in Europe 2011, DG Employment, Social Affairs and Equal Opportunities, Luxembourg: Publications. Office of the European Union

European Commission (2013), Towards Social Investment for Growth and Cohesion - including implementing the European Social Fund 2014-2020) (COM(2013) 83 final - Communication from the Commission to the European Parliament, the Council, the European Economic and Social Committee and the Committee of the Regions), European Commission, Brussels.

Eurostat (2015) Quality of Life: Facts and Views. (Eurostat Statistical Books). Luxembourg: Publications Office of the European Union.

Fahey, T, Whelan, C.T, Maitre,B. (2005), First European Quality of Life Survey: Income Inequalities and Deprivation, European Foundation for the Improvement of Living and Working Conditions. Office for Official Publications of the European Communities, Luxembourg.Kakwani and Silber, 2007

Layte, R., Maitre, B. and Whelan, C. T.; (2010) Living Conditions, Social Exclusion and Mental WellBeing. Office for Official Publications of the European Communities, Luxembourg.

Maître, B., Nolan, B. and Whelan, C. T (2014). 'L'indicateur EU2020 de suivi de la pauvreté et de exclusion : une analyse critique', Économie et Statistique, 469-470 :147-167.

Maître, B., Nolan, B. and Whelan, C.T. (2006). Reconfiguring the Measurement of Deprivation and Consistent Poverty in Ireland, ESRI Policy Research Series, No. 56. Dublin: The Economic and Social Research Institute.

Marmot, M. (2015) The Health Gap: The Challenge of an Unequal World. London: Bloomsbury.

Ministerio de Desarrollo Social de Chile (2015). CASEN 2013. Situacion de la Pobreza en Chile. Presentacion de la nueva metodologia de medicion de la pobreza y sintesis de los principales resultados.

http://observatorio.ministeriodesarrollosocial.gob.cl/documentos/Casen2013_Situacion_Pobreza_C hile.pdf

Mitra, S., \& Brucker, D. (2014). Poverty and Disadvantage through a multidimensional lens in the United States. Fordham University Discussion Paper No. 5.

Moisio, P. (2004), 'A latent class application to the multidimensional measurement of poverty', Quantity and Quality International Journal of Methodology, Vol. 38, No. 6, pp. 703-717.

National Action Plan for Social Inclusion 2007 - 2016 (NAPInclusion) (2007), Dublin: Stationery Office

National Economic and Social Council (NESC) (2009). Well-Being Matters: A Social Report for Ireland. Dublin: NESC.

Nolan B. and Whelan, C.T. (2011). Poverty and Deprivation in Europe. Oxford : Oxford University Press.

OECD (2015) How's Life? Measuring Well-being. Paris: OECD. DOI 10.1787/how_life-2015-en.

Pisati, M., Whelan, C.T., Lucchini, Maître, B. (2010), 'Mapping Patterns of Multiple Deprivation Using Self-organising Maps: AnApplication to EU_SILC Data for Ireland, Social Science Research, 39: 405418

Ravallion. M. (2011) 'On Multdimensional Indices of Poverty', Journal of Economic Inequality, 9: 23548 
Ringen, S. (1988). 'Direct and Indirect Measures of Poverty'. Journal of Social Policy, 17, 351-365. doi:10.1017/S0047279400016858.

Rose, D .and Harrison, E. 2007 'The European Socio-economic Classification: A New Social Class Schema for Comparative European Research' European Societies, 9,3: 459-490

Sen, A. K. (1979). 'Equality of What?', in S. McMurrin (ed.), Tanner Lectures on Human Values. CUP.

Sen, A. K. (1985). 'Well-Being, Agency and Freedom: The Dewey Lectures 1984'. The Journal of Philosophy, 82(4): 169-221.

Sen, A. K. (1992). Inequality Re-Examined. Oxford: Clarenden Press..

Sen, A. K. (1993) "Capability and Well-being," in Nussbaum and Sen (eds.), The Quality of Life, Oxford: Clarendon Press, pp. 30-53

Sen, A. (1999). Development as Freedom. Oxford: Oxford University Press.

Sen, A. (2009). The Idea of Justice. London: Allen Lane

Sponsorship Group on Measuring Progress, Well-being and Sustainable Development (2011). 'Multidimensional Measurement of the Quality of Life.' (available at http://ec.europa.eu/eurostat/documents/42577/43503/SpG-Final-report-Progress-wellbeingand-sustainable-deve)

Stiglitz, J., Sen, A. and Fitoussi, J-P. (2009) The Measurement of Economic Performance and Social Progress Revisited - Reflections and Overview, Sciences Po Publications, 2009-33, Sciences Po. (available at http://www.stiglitz-sen-fitoussi.fr/documents/overview-eng.pdf)

Townsend, P. (1979), Poverty in the United Kingdom. Harmondsworth: Penguin.

Watson, D., Maître, B. and Kingston, G. (2014). Developing a country typology for analysing quality of life in Europe. Luxembourg: Publications Office of the European Union.

Watson, D., Pichler, F., and Wallace, C. (2010). Subjective well-being in Europe (Second European Quality of Life Survey). Dublin: European Foundation for the Improvement of Living and Working Conditions.

Weber, Max (2010) The distribution of power within the community: Classes, Stände, Parties by Max Weber (Translated by Dagmar Waters, Tony Waters, Elisabeth Hahnke, Maren Lippke, Eva Ludwig-Glück, Daniel Mai, Nina Ritzi-Messner, Christina Veldhoen and Lucas Fassnacht ) in Journal of Classical Sociology (May 2010), 10(2): 137-152

Whelan, C. T. and Maître, B. (2005). 'Vulnerability and Multiple Deprivation Perspectives on Economic Exclusion in Europe: A Latent Class Analysis', European Societies, 7(3), 23-445.

Whelan, C. T. and Maître, B. (2012), Understanding Material Deprivation: A Comparative European Analysis, Research in Social Stratification and Mobility, 30: 489-503

Whelan, C. T. (2007). 'Understanding the Implications of Choice of Deprivation Index for Measuring Consistent Poverty in Ireland', Economic and Social Review, 38(2), 211-234.

Whelan, C. T., Nolan, B and Maitre, B (2014), 'Multidimensional Poverty Measurement in Europe: An Application of the Adjusted Headcount Approach', Journal of European Social Policy, Vol. 24, No. 2, pp.183-197.

Whelan, B. and Whelan, C.T. (1995) 'In What Sense is Poverty Multidimensional?', G. J. Room (Ed.), Beyond the Threshold.' The Measurement and Analysis of Social Exclusion, Bristol: Policy Press 
Whelan, C. T. (2010), 'Understanding the socio-economic distribution of multiple deptivatio: An application of self-organising maps, Research in Social Stratification and Mobility, 28:325-342

Williams, J, Murray. A, Whelan, C. T. (2014) 'Multidimensional Deprivation Among 9-Year Olds in Ireland: An Analysis of the Growing Up in Ireland Study'. Child Indicators Research, 7 (2):279-300. 
Figure 1: Percentage of adults experiencing QoL deficits by number of dimensions

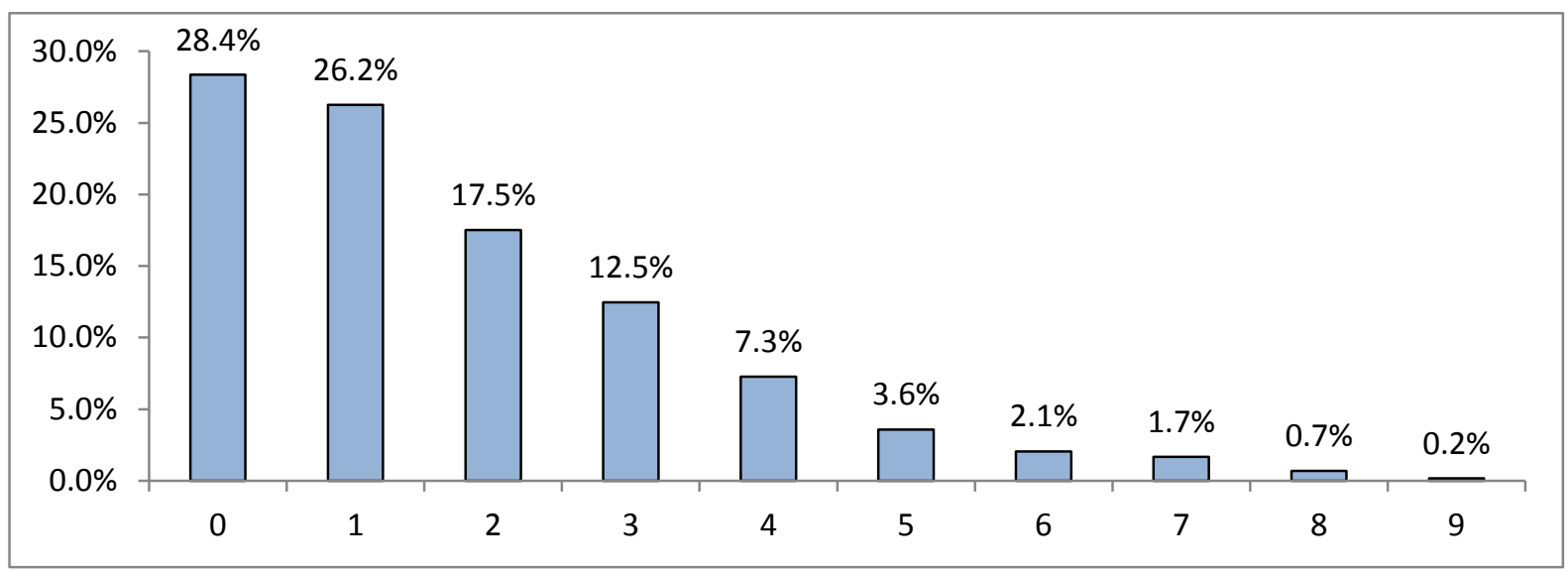

Source: SILC 2013 for Ireland, analysis by authors. Cases for whom QoL items available, all ages (with children assigned score of parents, $\mathrm{N}=8932$ ). 
Figure 2: Decomposition of QoL problems (AHCR) by dimension within social risk group

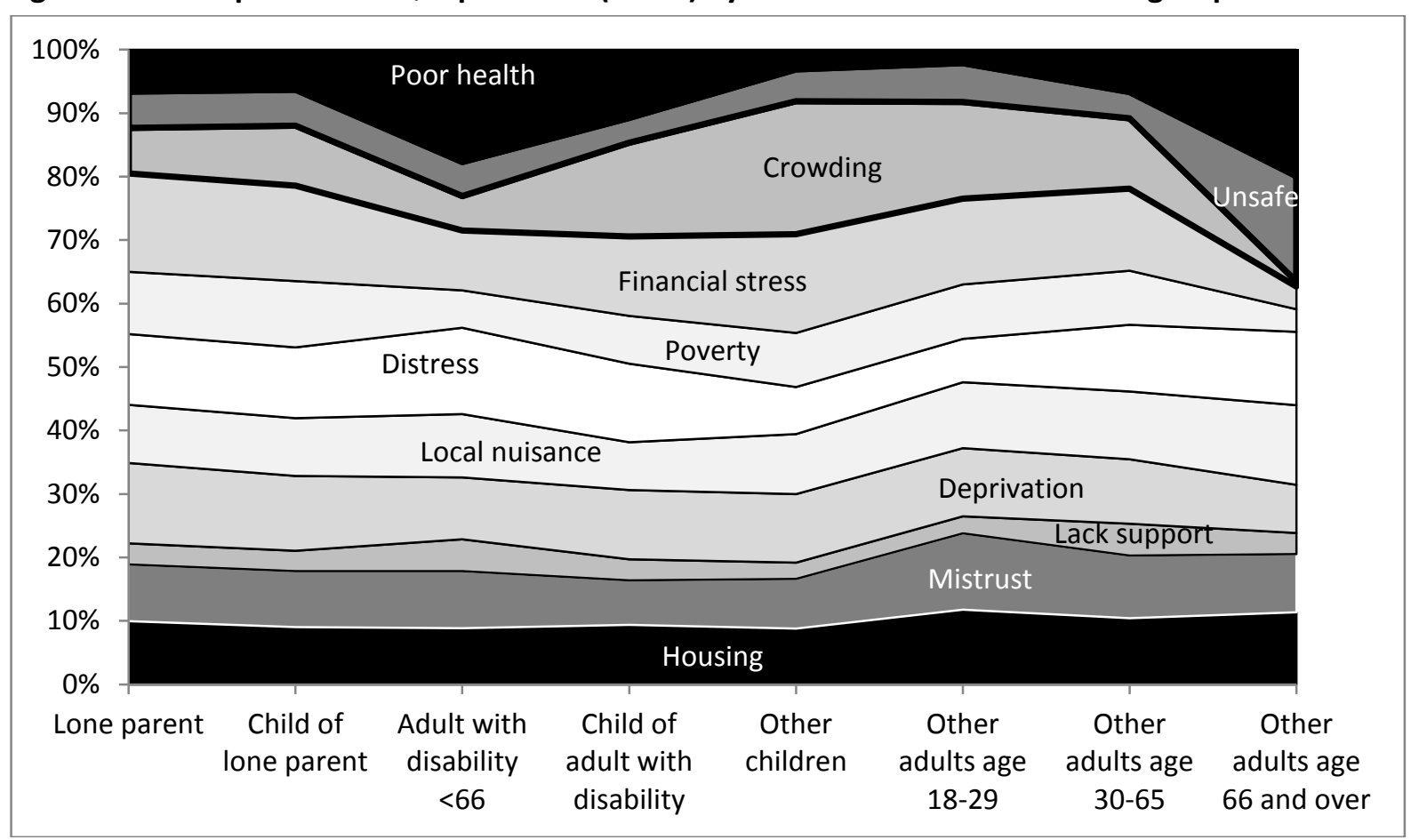

Source: SILC 2013, analysis by authors. N persons multidimensionally disadvantaged =1,458 with between 110 and 364 (age 51-64) in each social risk group. 
Figure 3: Relative Multidimensionality Quotient by Social Risk Group

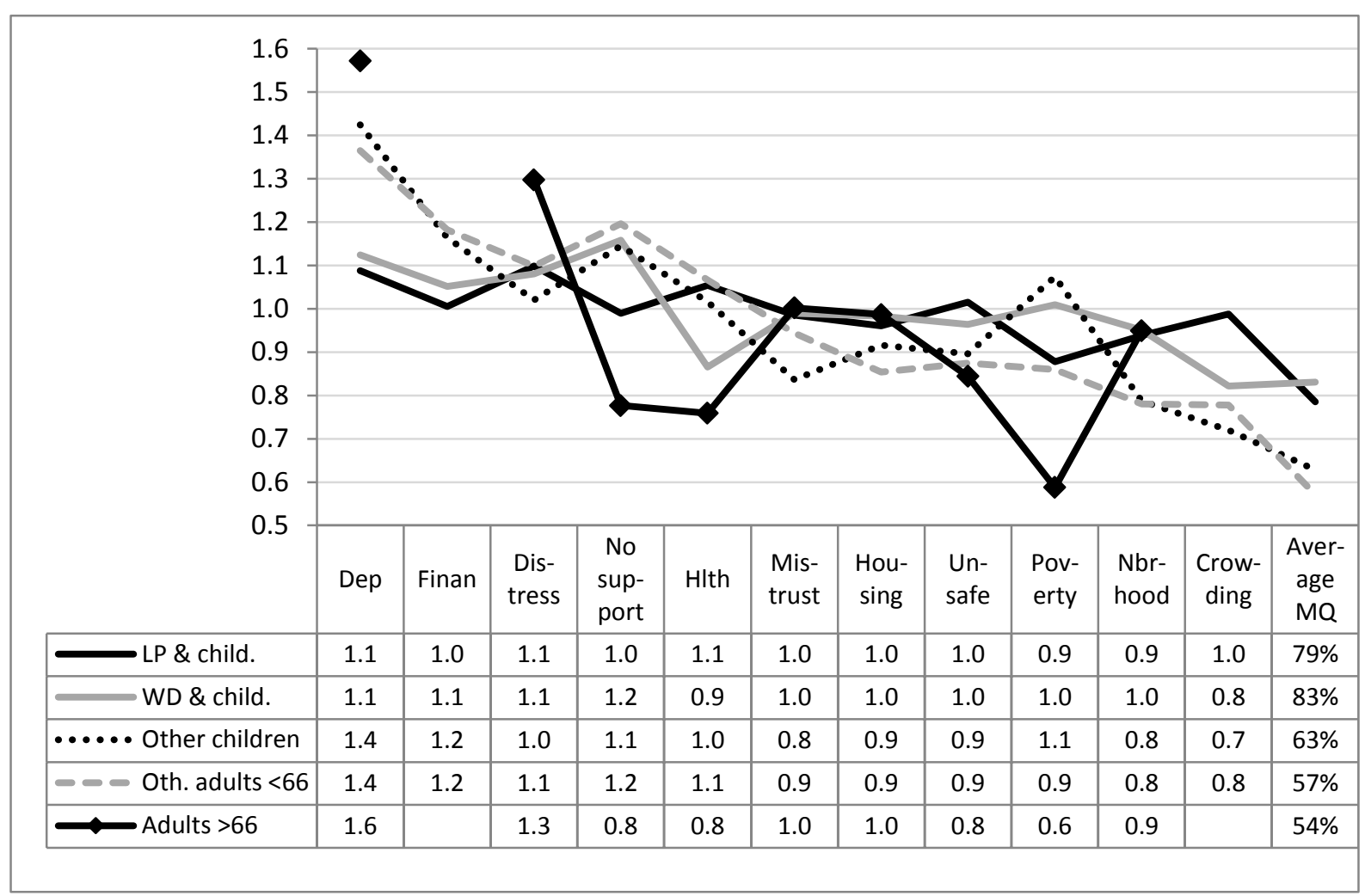

Source: SILC 2013, analysis by authors. $N$ persons multidimensionally disadvantaged $=1,458$ with between 110 and 364 (age 51-64) in social risk group. Too few cases to report results for financial stress and crowding among older adults. 
Table 1: Dimensions of quality of life and indicators of each dimension

\begin{tabular}{|c|c|c|}
\hline Dimension & Indicators & Threshold \\
\hline Income poverty & $\begin{array}{l}\text { Income poverty - in household with equivalised income below } 60 \% \text { of } \\
\text { median }\end{array}$ & $14.6 \%$ \\
\hline Deprivation & $\begin{array}{l}\text { Inability to afford } 4 \text { or more of } 11 \text { basic goods and services, including } \\
\text { adequate food, clothing, heating, replacing worn furniture and basic } \\
\text { social engagement. }\end{array}$ & $13.0 \%$ \\
\hline Financial strain & $\begin{array}{l}\text { Composite indicator - problems on } 4 \text { of } 5 \text { items: difficulty making ends } \\
\text { meet, housing costs burdensome, going into debt to meet ordinary living } \\
\text { expenses, arrears on mortgage/rent or utility bills and inability to save }\end{array}$ & $16.0 \%$ \\
\hline Health problems & Self-rated health is 'fair', 'bad' or 'very bad' & $19.8 \%$ \\
\hline Mental distress & $\begin{array}{l}\text { WHO 5-item indicator of mental distress: frequently feeling } \\
\text { nervous, depressed, down; infrequently feeling happy, calm }\end{array}$ & $16.1 \%$ \\
\hline Crowding & $\begin{array}{l}\text { Number of persons per room and number of persons per bedroom } \\
\text { (additive scale; threshold taken as score of } 1.24 \text { or higher on scale ranging } \\
\text { from } 0.06 \text { to } 2.06 \text { ). }\end{array}$ & $17.3 \%$ \\
\hline $\begin{array}{l}\text { Housing quality } \\
\text { problems }\end{array}$ & $\begin{array}{l}\text { Composite indicator - dwelling has problems with dampness and/or } \\
\text { insufficient light }\end{array}$ & $18.2 \%$ \\
\hline $\begin{array}{l}\text { Neighbourhood } \\
\text { problems }\end{array}$ & $\begin{array}{l}\text { Indicator based on three items - problems with noise, pollution and/or } \\
\text { crime in the area. }\end{array}$ & $20.2 \%$ \\
\hline $\begin{array}{l}\text { Institutional } \\
\text { mistrust }\end{array}$ & $\begin{array}{l}\text { Composite indicator based on three items: Low level of trust in political } \\
\text { system, legal system, police (threshold taken as score of } 2.1 \text { or higher on } \\
\text { scale from } 0 \text { to } 3 \text { ). }\end{array}$ & $16.1 \%$ \\
\hline $\begin{array}{l}\text { Lack of social } \\
\text { support }\end{array}$ & $\begin{array}{l}\text { A composite indicator based on two items: lacking someone to talk to and } \\
\text { unable to get help from others }\end{array}$ & $6.7 \%$ \\
\hline Lack of safety & $\begin{array}{l}\text { A single indicator based on one item, feeling 'very unsafe' walking in area } \\
\text { after dark. }\end{array}$ & $12.2 \%$ \\
\hline
\end{tabular}

Source: SILC 2013 data for Ireland, analysis by authors. Population aged 16 and over on whom we have data from a direct interview $(\mathrm{N}=5760)$. 
Table 2: Sizes of Social Risk Groups in 2013

\begin{tabular}{|l|c|}
\hline Social Risk Groups & Size of group \\
\hline Lone parent & $4 \%$ \\
\hline Child of lone parent & $6 \%$ \\
\hline Working age, disability* & $8 \%$ \\
\hline Child of working-age, disability & $5 \%$ \\
\hline Other children & $23 \%$ \\
\hline Young adults (18-29) & $6 \%$ \\
\hline Other adults (30-65) & $36 \%$ \\
\hline Adults 66+ & $12 \%$ \\
\hline Total & $100 \%$ \\
\hline
\end{tabular}

Source: SILC data for Ireland, 2013, weighted; analysis by authors. Cases for whom QoL items available, all ages (with children assigned score of parents, $\mathrm{N}=8932$ ). ${ }^{*}$ Disability is measured as having a health problem that for at least the last 6 months limited the person in terms of activities people usually do. 
Table 3: Level of QoL problems by Social Risk Group and decomposition of QoL by social risk group (SILC 2013, Ireland)

\begin{tabular}{|c|c|c|c|c|}
\hline Social Risk Groups & Headcount & Intensity & $\begin{array}{c}\text { Adjusted } \\
\text { Headcount } \\
\text { Ratio (AHCR) }\end{array}$ & $\begin{array}{l}\text { Decom- } \\
\text { position of } \\
\text { AHCR by } \\
\text { group }\end{array}$ \\
\hline Lone parent & $46 \%$ & $40 \%$ & $18 \%$ & $7 \%$ \\
\hline Child of lone parent & $48 \%$ & $42 \%$ & $20 \%$ & $12 \%$ \\
\hline Working age, disability & $54 \%$ & $41 \%$ & $22 \%$ & $17 \%$ \\
\hline Child of working-age, disability & $53 \%$ & $42 \%$ & $22 \%$ & $11 \%$ \\
\hline Other children & $24 \%$ & $35 \%$ & $8 \%$ & $18 \%$ \\
\hline Young adults (18-29) & $26 \%$ & $35 \%$ & $9 \%$ & $5 \%$ \\
\hline Other adults (30-65) & $18 \%$ & $35 \%$ & $7 \%$ & $23 \%$ \\
\hline Adults $66+$ & $20 \%$ & $33 \%$ & $6 \%$ & $7 \%$ \\
\hline Total & $27.8 \%$ & $37.6 \%$ & $10.5 \%$ & $100 \%$ \\
\hline
\end{tabular}

Source: SILC data for Ireland, 2013, weighted; analysis by authors. Cases for whom QoL items available, all ages (with children assigned score of parents, $\mathrm{N}=8932$ ). 
Table 4: Percentage of people above the threshold on each Quality of Life Indicator and contribution of the indicator to the AHCR

\begin{tabular}{|l|c|c|c|}
\hline Indicator & $\begin{array}{c}\text { \% above } \\
\text { threshold on } \\
\text { indicator }\end{array}$ & $\begin{array}{c}\text { Contribution } \\
\text { of indicator to } \\
\text { AHCR }\end{array}$ & $\begin{array}{c}\text { Of those above item } \\
\text { threshold, \% with 3+ } \\
\text { QoL problems }\end{array}$ \\
\hline Crowding & $24.9 \%$ & $11.3 \%$ & $52.1 \%$ \\
\hline Neighbourhood problems & $20.0 \%$ & $9.8 \%$ & $56.4 \%$ \\
\hline Lack of safety & $11.4 \%$ & $5.8 \%$ & $59.0 \%$ \\
\hline Housing quality problems & $18.3 \%$ & $9.7 \%$ & $61.1 \%$ \\
\hline Income poverty & $14.9 \%$ & $8.0 \%$ & $61.4 \%$ \\
\hline Health problems & $16.5 \%$ & $9.0 \%$ & $62.7 \%$ \\
\hline Institutional mistrust & $16.3 \%$ & $8.9 \%$ & $62.8 \%$ \\
\hline Lack of social support & $5.9 \%$ & $3.8 \%$ & $73.9 \%$ \\
\hline Mental distress & $16.3 \%$ & $10.7 \%$ & $75.4 \%$ \\
\hline Financial strain & $19.2 \%$ & $12.6 \%$ & $75.5 \%$ \\
\hline Deprivation & $14.1 \%$ & $10.5 \%$ & $85.8 \%$ \\
\hline
\end{tabular}

Source: SILC 2013 data for Ireland, analysis by authors. Cases for whom QoL items available, all ages (with children assigned score of parents, $\mathrm{N}=8932$ ). 